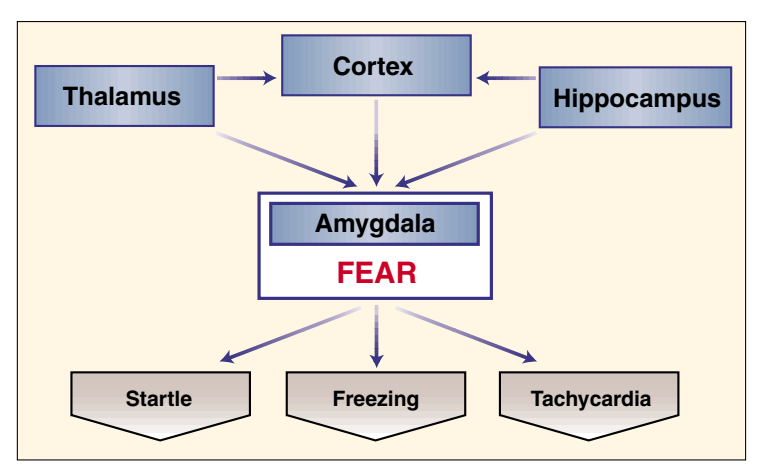

Fig. 2. Simplified neural circuit mediating fear. The amygdala receives multiple inputs and organizes a coherent defensive strategy to threat, including the example responses shown.

er, they showed enhanced fear in two other forms of fear conditioning. First, in trace conditioning, in which a one-second delay was inserted between the termination of the tone and onset of the shock, mutant mice showed enhanced conditioning relative to normal controls. Second, the authors tested the effect of decreasing the signal value of a cue, making it an imperfect predictor of foot shock. Normal mice show a reduced freezing response to this partially conditioned cue. In contrast, the mutant mice showed equally high levels of fear to the partially and normally conditioned cues, which can be regarded as inappropriate anxiety. Thus, these mice were predisposed to be hyperanxious but exhibited only selective alterations in learned fear ${ }^{2}$. These findings are in many ways reminiscent of the nonselective genetic predisposition proposed to exist for human anxiety disorders.

How does this $\gamma 2$ mutation affect the circuitry involved in fear learning? Rats and humans with extensive damage to the amygdala seem to lose the capacity to experience fear, and the hippocampus is also involved in fear learning, probably via its descending projections to the amygdala ${ }^{11-13}$ (Fig. 2). In generating anxiety, the amygdala requires converging information from several other structures, notably the hippocampus and cortex. Crestani et al. ${ }^{2}$ found that the mutants showed pronounced reductions in benzodiazepine binding in cortical areas, the hippocampus and, to a lesser degree, the amygdala. Although benzodiazepines do not bind the $\gamma$ subunit directly, GABA receptors lacking the $\gamma$ subunit fail to cluster and may not localize properly to synapses, which may account for these results. In addition, two tasks that have been proposed to depend on the hippocampus, passive avoidance (see Fig. $5 \mathrm{c}$ of Crestani et al. ${ }^{2}$ ) and trace fear conditioning, were enhanced in the mutants. Based on these data, the authors suggest that the hippocampus (rather than the amygdala) is the probable source of increased anxiety in these animals.

We believe this conclusion to be premature for several reasons. Two wellestablished forms of hippocampus-dependent aversive learning, the Morris water maze and contextual fear conditioning ${ }^{14}$, were normal in $\gamma 2$ mutant mice. In addition, there is no consensus that passive avoidance behavior depends on the hippocampus (although some studies suggest it does), nor is it clear that trace fear conditioning at the short delay interval used in the present study requires the hippocampus. Thus, we believe that the preponderance of the behavioral evidence suggests that hippocampal circuits normally involved in learning are largely intact in these mutants, but that the amygdala-or one of its inputs-is overactive. Given that the mutation altered GABAergic function in hippocampus and cortex, it is possible that anxiety responses were altered because the amygdala received aberrant input from these regions. Obviously, additional work will be required to test this speculation.

Regardless of the circuitry involved, however, $\gamma 2$ mutant mice may represent a good genetic model of some forms of anxiety predisposition because they are likely to overreact to many anxiety-provoking situations. Such genetic models ${ }^{2,15}$ are important in furthering the study of innate contributors to anxiety disorders. First, the mice offer the promise of a genetic model of the anxiety-predisposed human, which may be useful in improving drug discovery. Rather than examining the effects of novel anxiolytics on normal rats, one may examine genetic models in hopes of finding agents selective for abnormal anxiety. Second, these mice offer easily testable predictions about mutations that may be found in anxiety patients. Finally, although the identification of genetic predisposing factors would certainly be a major advance, it is clear that genes alone will not explain human anxiety. These mutant mice should therefore be a valuable model for testing ideas about how genes and environment interact to produce this condition.

1. Fendt, M. \& Fanselow, M. S. Neurosci. Biobehav. Rev. 23, 743-760 (1999).

2. Crestani, F. et al. Nat. Neurosci. 2, 833-839 (1999).

3. Resnick, H. S. et al. J. Consulting Clin. Psychol. 61, 984-991 (1993).

4. Skre, I., Onstad, S., Torgersen, S., Lygren, S. \& Kringlen, E. Acta Psych. Scan. 88, 85-92 (1993).

5. True, W. R. et al. Arch. Gen. Psychiatry 50, 257-264 (1993).

6. Craske, M. G. Anxiety Disorders: Psychological Approaches to Theory and Treatment (Basic Books/Westview, Boulder, Colorado, 1999).

7. Kendler, K. S. et al. Arch. Gen. Psychiatry 52, 374-382 (1995).

8. Kagan, J., Reznick, J. S. \& Snidman, N. Child Devel. 58, 1459-1473 (1987).

9. Coplan, J. D. \& Lydiard, R. B. Biol. Psychiatry 44, 1264-1276 (1998).

10. Clement Y. \& Chapouthier, G. Neurosci. Biobehav. Rev. 22, 623-633 (1998).

11. Maren, S. \& Fanselow, M. S. J. Neurosci. 15, 7548-7564 (1995).

12. Phillips, R. G. \& LeDoux, J. E. Behav. Neurosci. 106, 274-285 (1992).

13. Anagnostaras, S. G., Maren, S. \& Fanselow, M. S. J. Neurosci. 19, 1106-1114 (1999).

14. Kim, J. J. \& Fanselow, M. S. Science 256, 675-677 (1992).

15. Heisler, L. K. et al. Proc. Natl. Acad. Sci. USA 95, 15049-15054 (1998).

\title{
Synaptic physiology in C. elegans
}

Although $C$. elegans is a powerful genetic model, its one-millimeter length has made functional data difficult to obtain. In this issue (page 79l), Richmond and Jorgensen report patch-clamp electrophysiology in $C$. elegans muscle. They combined physiology with genetic analysis to identify three receptors that function at the neuromuscular junction, a simple polyinnervated synapse. In this dissected worm, muscles are immunostained red, and GABAergic neurons of the ventral nerve cord express green fluorescent protein (photo by Jean-Louis Bessereau).

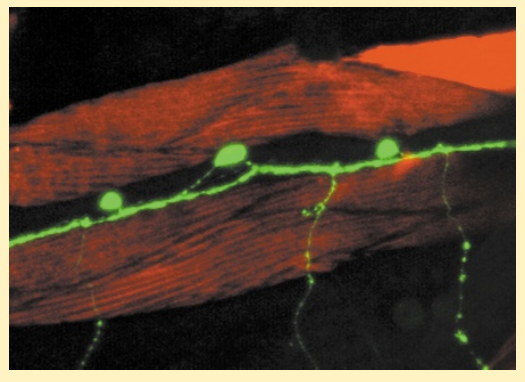

Sandra Aamodt 